\title{
Soroprevalência de Toxoplasma gondii em equídeos do Nordeste do Brasil ${ }^{1}$
}

\author{
Neurisvan R. Guerra²*, Jonatas C. Almeida ${ }^{3}$, Elâine L. Silva ${ }^{3}$, Edson M. Silva², \\ José A.M. Santos ${ }^{2}$, Raphael Lepold ${ }^{2}$, Rinaldo A. Mota ${ }^{3}$ e Leucio C. Alves ${ }^{2}$
}

\begin{abstract}
Guerra N.R., Almeida J.C., Silva E.L., Silva E.M., Santos J.A.M., Lepold R., Mota R.A. \& Alves L.C. 2018. [Seroprevalence of Toxoplasma gondii in equidae from Northeast Brazil.] Soroprevalência de Toxoplasma gondii em equídeos do Nordeste do Brasil. Pesquisa Veterinária Brasileira 38(3):400-406. Laboratório de Doenças Parasitárias dos Animais Domésticos, Departamento de Medicina Veterinária, Universidade Rural de Pernambuco, Rua Dom Manoel de Medeiros s/n, Dois Irmãos, Recife, PE 52171-900, Brazil. E-mail: neurisvan.guerra@hotmail.com

This paper reports seroprevalence of toxoplasmosis in horses kept in different forms of breeding system in the state of Pernambuco. For that, 400 blood serum samples from clinically healthy horses were analyzed through the test of modified agglutination (MAT) considering cut-off of 1:25. Data related to the characteristics of the animals and herds, breeding system, presence of other animals, age, gender, breed, aptitude, and physical conditions were collected throughout investigative surveys. IgG anti-Toxoplasma gondii antibodies were detected in $12.5 \%$ (50/400) of the analyzed animals. In the 12 studied towns, there was a positivity in 91. $67 \%(11 / 12)$ with a variation between $4 \%$ and $33.3 \%$. When the risk factors were evaluated, only the mesoregion factor $(\mathrm{p}=0.029)$ had an association with the infection, particularly the Zona da Mata region ( $\mathrm{OR}=3$ ), followed by the Recife Metropolitan Area (OR=2.2), Agreste region $(\mathrm{OR}=1.7)$ and Sertão region $(\mathrm{OR}=1)$. The results shows the presence of the parasites on the studied area, which may represent a link with the transmission chain of toxoplasmosis which has influence on the public health system, considering that Brazil is the eighth greatest exporter of equine meat in the world.

INDEX TERMS: Seroprevalence, Toxoplasma gondii, equidae, Northeast Brazil, risk factor, public health, zoonosis, parasitic disease, serology, parasitoses.
\end{abstract}

RESUMO.- Este estudo teve como objetivo determinar a soroprevalência da toxoplasmose em equídeos mantidos em diferentes formas de manejo no estado de Pernambuco. Para tanto, um total de 400 amostras de soro sanguíneo de equídeos clinicamente saudáveis foram analisados através do teste de aglutinação modificado (MAT) considerando-se cut-off de 1:25. Dados referentes às características dos animais e dos

\footnotetext{
${ }^{1}$ Recebido em 22 de novembro de 2016.

Aceito para publicação em 10 de abril de 2017.

Pesquisa de doutorado com apoio FACEPE.

2 Laboratório de Doenças Parasitárias dos Animais Domésticos, Departamento de Medicina Veterinária, Universidade Federal Rural de Pernambuco (UFRPE), Rua Dom Manoel de Medeiros s/n, Dois Irmãos, Recife, PE 52171-900, Brasil. *Autor para correspondência: neurisvan.guerra@hotmail.com

${ }^{3}$ Laboratório de Doenças Infecciosas dos Animais Domésticos, Departamento de Medicina Veterinária, Universidade Federal Rural de Pernambuco, Rua Dom Manoel de Medeiros s/n, Dois Irmãos, Recife, PE 52171-900, Brasil.
}

rebanhos, sistema de criação, presença de outros animais, idade, sexo, raça, aptidão, condição física foram coletados por meio de questionários investigativos. Anticorpos IgG anti-Toxoplasma gondii foram detectados em $12,5 \%$ (50/400) dos animais analisados. Dos 12 municípios estudados, houve positividade em $91,67 \%$ (11/12) com variação entre $4,4 \%$ e $33,3 \%$. Quando avaliados os fatores de risco, apenas o fator mesorregião $(p=0,029)$ apresentou associação com a infecção, particularmente Zona da Mata $(\mathrm{OR}=3)$, seguida de Região Metropolitana do Recife (OR=2,2), Agreste (OR=1,7) e Sertão $(O R=1)$. Os resultados revelam a presença do parasito na área estudada, o que pode representar um elo na cadeia de transmissão da toxoplasmose a qual tem repercussão em saúde pública tendo em vista que o Brasil é o oitavo maior exportador de carne equina do mundo.

TERMOS DE INDEXAÇÃO: Soroprevalência, Toxoplasma gondii, equídeos, Nordeste do Brasil, fator de risco, saúde pública, zoonose, doença parasitária, sorologia, parasitoses. 


\section{INTRODUÇÃO}

A toxoplasmose é uma antropozoonose parasitária causada pelo protozoário Toxoplasma gondii, parasita intracelular obrigatório (Tenter et al. 2000), que acomete todos os animais homeotérmicos (Webster 2010) distantes da escala zoológica, tendo o gato doméstico como hospedeiro definitivo (Dubey \& Jones 2008).

Estima-se que mais de um terço da população mundial encontra-se infectada por T. gondii variando de acordo com as condições econômicas e hábitos culturais das populações estudadas (Aspinall et al. 2002).

Entre as espécies domésticas, os equinos são os mais resistentes à infecção por T. gondii, podendo causar encefalite (Coiro et al. 2012) além de sinais como hiperirritabilidade, incoordenação, desordens oculares e aborto que podem ser observados (Moura et al. 2016).

Nesse contexto, o consumo de carne mal cozida está bem estabelecido como um importante fator de risco para infecção por T. gondii na população humana em todo o mundo (Boughattas et al. 2011). Embora o consumo de carne equina apresente pouca importância epidemiológica, tem-se observado um aumento no consumo de carne de equídeos no Brasil (Coiro et al. 2012) que é um grande distribuidor do produto, sendo o oitavo maior exportador mundial (Brasil 2016).

Vários testes sorológicos para detecção de anticorpos IgG anti-T. gondii em equídeos têm sido realizados na identificação de animais sororreagentes em todo o mundo (Ghazy et al. 2007, Kouam et al. 2010), mostrando prevalências que variam entre zero a 90\% (Uggla et al. 1990, Hejlíček \& Literák 1994, Jakubek et al. 2006, Tassi 2007, Balkaya et al. 2011, Oliveira Filho et al. 2012, Miao et al. 2013, Gharekhani 2014), na dependência do teste utilizado e local de estudo (Dubey et al. 2014).

Da mesma forma, no Brasil, estudos sorológicos apontam diferentes prevalências com variação entre $0 \%$ e 70\% (Ishizuka et al. 1975, Silva et al. 1981, Larangeira et al. 1985, Costa et al. 1986, Braccini et al. 1992, Barcelos et al. 1997, Vidotto et al. 1997, Gazêta et al. 1997, Garcia et al. 1999, Mendonça et al. 2001, Navarro et al. 2002, Carletti et al. 2002, Naves et al. 2005, Villalobos et al. 2005, LocatelliDittrich et al. 2006, Coiro et al. 2012, Oliveira Filho et al. 2012, Evers et al. 2013, Oliveira et al. 2013, Valença et al. 2015).

Considerando a importância da equideocultura no Brasil aliada à repercusão da toxoplasmose em saúde pública, este estudo tem como objetivo determinar a soroprevalência da toxoplasmose em equídeos mantidos em diferentes formas de manejo.

\section{MATERIAL E MÉTODOS}

Área de estudo e animais. Esse trabalho foi realizado no estado de Pernambuco $\left(8^{\circ} 4^{\prime} 14^{\prime \prime} \mathrm{S}, 37^{\circ} 15^{\prime} 57^{\prime \prime}\right.$ ) ) que está localizado na região Nordeste do Brasil e é dividido em quatro mesorregiões, a saber: Região Metropolitana do Recife, Zona da Mata, Agreste e Sertão (IBGE 2010). Quanto à população de equídeos, o estado possui 189.757 animais (IBGE 2006).

Considerando-se o número de equídeos de Pernambuco ( $\mathrm{n}>10.000$ ), com uma prevalência estimada de $50 \%$, margem de erro de $\pm 5 \%$ e um nível de confiança de $95 \%$, o cálculo amostral resultou em 384 amostras.

Um total de 400 amostras de soro de equídeos clinicamente saudáveis, incluindo equinos $(387 / 400)$, muares $(4 / 400)$ e asininos (9/400) de ambos os sexos com idade de até 25 anos foram analisadas. Entre os equídeos utilizados, havia animais de reprodução bem como atletas que participavam principalmente de vaquejadas, os quais eram mantidos, na sua maioria, semiestabulados ou estabulados. Além desses, existiam outros destinados ao trabalho no campo sendo a maior parte criada a campo. Esses animais eram provenientes de 41 propriedades rurais (Quadro 1), de quatro diferentes mesorregiões (Fig.1) do estado de Pernambuco ( $\left.8^{\circ} 4^{\prime} 14^{\prime \prime} S, 37^{\circ} 15^{\prime} 57^{\prime \prime} 0\right)$.

Dados referentes às características dos animais e dos rebanhos, sistema de criação, presença de outros animais, idade, sexo, raça, aptidão, condição física foram coletados por meio de questionários investigativos. 0 estudo foi aprovado pela Comissão de Ética Para o Uso de Animais (CEUA) da Universidade Federal Rural de Pernambuco sob a licença de número 036/2014.

Teste de aglutinação modificada. 0 teste de Aglutinação Modificado foi realizado de acordo com técnica descrita por Desmonts \& Remington (1980) considerando-se o cut-off de 1:25 (AlvaradoEsquivel et al. 2012).

$\mathrm{O}$ antígeno utilizado foi preparado a partir de cepa $\mathrm{RH}$ de Toxoplasma gondii obtido de camundongos previamente inoculados no Laboratório de Doenças Infecciosas dos Animais Domésticos, Universidade Federal Rural de Pernambuco.

As amostras de soro foram diluídas (1:25) em tampão fosfato salino (PBS) contendo 2- Mercaptoetanol 0,2M e adicionados $50 \mu \mathrm{L}$ da diluição em poços de placas de poliestireno de fundo em U. Em seguida, adicionou-se a cada diluição de soro, $50 \mu \mathrm{L}$ dos taquizoítos de T. gondii preservados com formalina sendo mixados imediatamente com um pipetador por várias vezes. Após isso, as placas foram cobertas e incubadas em estufa a $37^{\circ} \mathrm{C}$ por 16 horas.

Em todas as reações foram usados soros de equinos como controles positivos e negativos, previamente testados e confirmados (Valença et al. 2015).

Quanto aos resultados, foram considerados positivos quando se visualizava botão de contorno definido no fundo do poço da placa enquanto que resultado negativo na ausência de botão.

Análise dos dados. Para a análise dos fatores de risco associados à infecção, primeiramente, realizou-se uma análise univariada e, posteriormente, uma análise de regressão logística considerando como variável dependente o resultado obtido na sorologia (positiva ou negativa). As variáveis independentes ou explanatórias consideradas no modelo foram aquelas que apresentaram significância estatística inferior a 0,20. 0 programa EpiInfo $^{\mathrm{TM}} 7$ foi utilizado para a execução dos cálculos estatísticos e o nível de significância adotado foi de 5,0\%. 


\section{RESULTADOS}

Anticorpos IgG anti-Toxoplasma gondii foram detectados em 12,5\% (50/400) dos animais analisados, sendo identificados títulos de 1:25 e $1: 50$ em 72\% (36/50) e 28\% (14/50), respectivamente. Dos 12 municípios estudados, houve positividade em 91,67\% (11/12) os quais apresentaram variação entre 4,4\% e 33,3\%.

Quando avaliados os fatores de risco, apenas o fator mesorregião $(p=0,029)$ apresentou associação com a infecção, particularmente Zona da Mata (OR=3), seguida de RMR $(\mathrm{OR}=2,2)$, Agreste $(\mathrm{OR}=1,7)$ e Sertão (OR=1) (Quadro 2).

\section{DISCUSSÃO}

A prevalência de 12,5\% de anticorpos IgG anti-Toxoplasma gondii aqui observada foi superior aos resultados encontrados em estudos na Grécia (Kouam et al. 2010), Turquia (Karatepe et al. 2010), República Tcheca (Hejlíček \& Literák 1994) e Brasil (Oliveira Filho et al.2012), que relataram taxas de prevalência variando entre $1,8 \%$ e $8,0 \%$ e inferior àquelas observadas no Egito (Ghazy et al. 2007), Itália (Rinaldi \& Scala 2008) e Iran (Tavalla et al. 2015) com prevalências variando entre $29 \%$ e $48,5 \%$.

Quadro 1. Coordenadas geográficas das propriedades no estado de Pernambuco

\begin{tabular}{|c|c|c|c|}
\hline Ponto & Município & Latitude & Longitude \\
\hline 1 & Bodocó 1 & $-0745^{\prime} 08,97415^{\prime \prime}$ & -39 58'07,85099" \\
\hline 2 & Bodocó 2 & $-0744^{\prime} 45,50133^{\prime \prime}$ & $-4000^{\prime} 26,96469^{\prime \prime}$ \\
\hline 3 & Bodocó 3 & $-0744^{\prime} 41,45777^{\prime \prime}$ & $-4000^{\prime} 34,28611^{\prime \prime}$ \\
\hline 4 & Bodocó 4 & $-0744^{\prime} 41,50432 "$ & $-4001^{\prime} 00,84211^{\prime \prime}$ \\
\hline 5 & Bodocó 5 & $-0746^{\prime} 18,80425^{\prime \prime}$ & $-3957^{\prime} 37,17433^{\prime \prime}$ \\
\hline 6 & Bodocó 6 & $-0745^{\prime} 58,74057^{\prime \prime}$ & $-3956^{\prime} 54,87055^{\prime \prime}$ \\
\hline 7 & Cabo 1 & -08 18' 02,23575" & $-3503^{\prime} 29,12380 "$ \\
\hline 8 & Camocim 1 & $-0820^{\prime} 40,54688^{\prime \prime}$ & $-3546^{\prime} 38,39455^{\prime \prime}$ \\
\hline 9 & Camocim 2 & $-0820^{\prime} 57,54059^{\prime \prime}$ & $-3546^{\prime} 31,18511^{\prime \prime}$ \\
\hline 10 & Camocim 3 & $-0820^{\prime} 26,96303^{\prime \prime}$ & $-3546^{\prime} 37,54494^{\prime \prime}$ \\
\hline 11 & Igarassu 1 & -07 51' 56,09086" & $-3455^{\prime} 41,84914^{\prime \prime}$ \\
\hline 12 & Itamaracá 1 & $-0742^{\prime} 52,90505^{\prime \prime}$ & $-3450^{\prime} 14,29776^{\prime \prime}$ \\
\hline 13 & Jaboatão 1 & $-0810^{\prime} 36,26206^{\prime \prime}$ & -35 00'09,85791" \\
\hline 14 & Lagoa 1 & $-0750^{\prime} 44,88072 "$ & $-3517^{\prime} 49,07876^{\prime \prime}$ \\
\hline 15 & Lagoa 2 & $-0750^{\prime} 42,51450^{\prime \prime}$ & -35 17' 51,91043" \\
\hline 16 & Lagoa 3 & $-0750 \prime 42,52201^{\prime \prime}$ & $-3517^{\prime} 48,02910^{\prime \prime}$ \\
\hline 17 & Lagoa 4 & $-0750 \prime 17,67030 "$ & $-3517^{\prime} 41,46126^{\prime \prime}$ \\
\hline 18 & Limoeiro 1 & -07 53’ 39,43967" & $-3525^{\prime} 42,60819^{\prime \prime}$ \\
\hline 19 & Limoeiro 2 & $-0753 \prime 38,56796 "$ & $-3525^{\prime} 38,30602^{\prime \prime}$ \\
\hline 20 & Limoeiro 3 & -07 53'29,57279" & $-3525^{\prime} 58,67605^{\prime \prime}$ \\
\hline 21 & Limoeiro 4 & $-0753^{\prime} 49,95831^{\prime \prime}$ & $-3526^{\prime} 27,21517^{\prime \prime}$ \\
\hline 22 & Limoeiro 5 & -07 53'24,69632" & $-3525^{\prime} 56,77255^{\prime \prime}$ \\
\hline 23 & Moreno 1 & $-0806^{\prime} 01,10375^{\prime \prime}$ & $-3505^{\prime} 04,46294^{\prime \prime}$ \\
\hline 24 & Ouricuri 1 & $-0750^{\prime} 21,03414^{\prime \prime}$ & $-4004^{\prime} 01,04681^{\prime \prime}$ \\
\hline 25 & Ouricuri 2 & $-0751^{\prime} 00,44716^{\prime \prime}$ & $-4003^{\prime} 34,97971^{\prime \prime}$ \\
\hline 26 & Ouricuri 3 & $-0750^{\prime} 50,23540^{\prime \prime}$ & -40 02' 20,12848" \\
\hline 27 & Ouricuri 4 & $-0750^{\prime} 49,13946^{\prime \prime}$ & -40 02'00,87680" \\
\hline 28 & Ouricuri 5 & $-0750^{\prime} 23,58455^{\prime \prime}$ & $-4001^{\prime} 37,55474^{\prime \prime}$ \\
\hline 29 & Ouricuri 6 & -0750 '07,91591" & -40 01' 13,18492" \\
\hline 30 & Ouricuri 7 & $-0749^{\prime} 39,90624 "$ & $-4000^{\prime} 36,62414^{\prime \prime}$ \\
\hline 31 & Ouricuri 8 & $-0750^{\prime} 00,46400^{\prime \prime}$ & $-4001^{\prime} 07,85356^{\prime \prime}$ \\
\hline 32 & Paudalho 1 & $-0755^{\prime} 59,59128^{\prime \prime}$ & -35 07' 50,09376" \\
\hline 33 & Paudalho 2 & $-0755^{\prime} 42,71233^{\prime \prime}$ & -35 08'22,37079" \\
\hline 34 & Surubim 1 & $-0751^{\prime} 07,15375^{\prime \prime}$ & $-3545^{\prime} 36,75855^{\prime \prime}$ \\
\hline 35 & Surubim 2 & -07 51' 01,29399" & $-3544^{\prime} 41,13232^{\prime \prime}$ \\
\hline 36 & Surubim 3 & $-0749^{\prime} 55,25134^{\prime \prime}$ & $-3546^{\prime} 41,70498^{\prime \prime}$ \\
\hline 37 & Surubim 4 & $-0749^{\prime} 53,96314^{\prime \prime}$ & $-3544^{\prime} 44,30235^{\prime \prime}$ \\
\hline 38 & Surubim 5 & $-0751^{\prime} 21,34232 "$ & $-3544^{\prime} 21,74619^{\prime \prime}$ \\
\hline 39 & Surubim 6 & -0750 '05,30249" & -35 46' 30,58097" \\
\hline 40 & Surubim 7 & $-0750^{\prime} 11,13665^{\prime \prime}$ & $-3544^{\prime} 37,30367^{\prime \prime}$ \\
\hline 41 & Surubim 8 & $-0749^{\prime} 48,91579^{\prime \prime}$ & $-3544^{\prime} 38,53657^{\prime \prime}$ \\
\hline
\end{tabular}




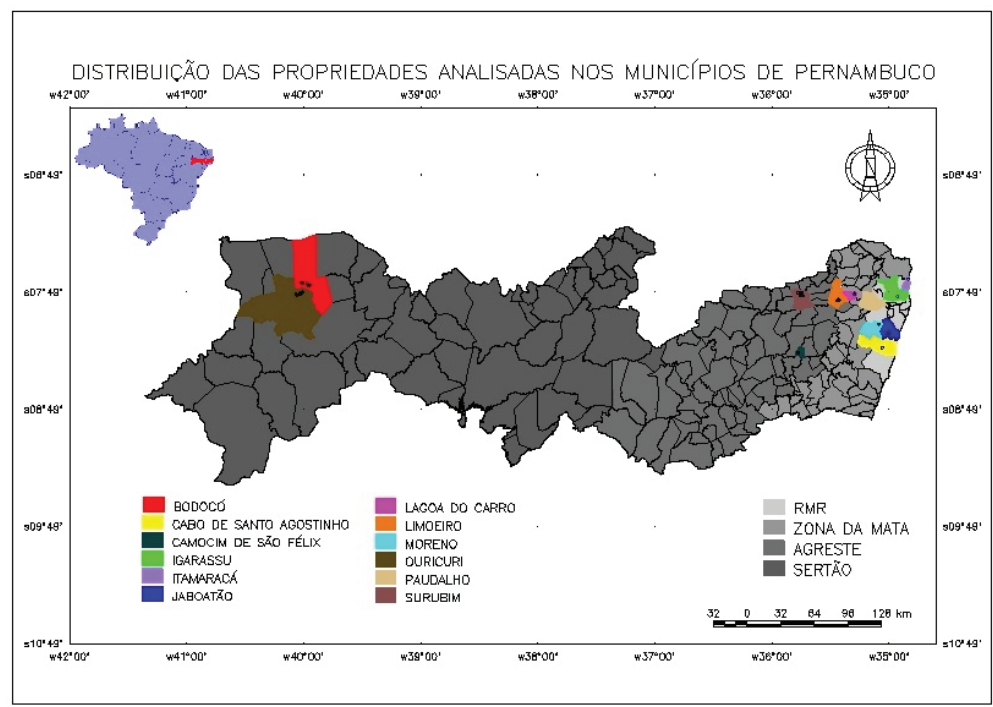

Fig.1. Distribuição das propriedades nas mesorregiões do estado de Pernambuco.

Quadro 2. Fatores de risco associados à infecção por Toxoplasma gondii em equídeos

\begin{tabular}{|c|c|c|c|c|c|c|}
\hline \multirow{2}{*}{ Variáveis } & \multirow{2}{*}{$\mathrm{N}$} & \multirow{2}{*}{\multicolumn{2}{|c|}{$\begin{array}{c}\text { Sorologia } \\
\text { positiva }\end{array}$}} & \multirow{2}{*}{ Valor P } & \multirow{2}{*}{$\begin{array}{l}\text { Regressão logística } \\
\text { OR (IC 95\%) }\end{array}$} & \multirow{2}{*}{ Valor $\mathrm{P}$} \\
\hline & & & & & & \\
\hline \multicolumn{7}{|l|}{ Alimentação } \\
\hline Sem suplementação & 89 & 11 & $(12,4 \%)$ & $0,844^{\mathrm{a}}$ & & \\
\hline Com suplementação & 170 & 23 & $(13,5 \%)$ & & & \\
\hline Mista & 141 & 16 & $(11,3 \%)$ & & & \\
\hline \multicolumn{7}{|l|}{ Espécie } \\
\hline Equina & 387 & 48 & $(12,4 \%)$ & & 1 & \\
\hline Asinina & 4 & 2 & $(50,0 \%)$ & $0,040^{\mathrm{a}}$ & $7,0(0,9-51,3)$ & 0,053 \\
\hline Muar & 9 & 0 & $(0,0 \%)$ & & $* *$ & 0,973 \\
\hline \multicolumn{7}{|l|}{ Idade (anos) } \\
\hline$<2,5$ & 90 & 8 & $(8,9 \%)$ & $0,339^{a}$ & & \\
\hline Entre 2,5 e 11 & 276 & 39 & $(14,1 \%)$ & & & \\
\hline$\geq 11$ & 34 & 3 & $(8,8 \%)$ & & & \\
\hline \multicolumn{7}{|l|}{ Presença de gatos } \\
\hline Sim & 28 & 4 & $(14,3 \%)$ & $0,766^{\mathrm{b}}$ & & \\
\hline Não & 372 & 46 & $(12,4 \%)$ & & & \\
\hline \multicolumn{7}{|l|}{ Raça de equinos } \\
\hline Mangalarga (ML) & 5 & 1 & $(20,0 \%)$ & $0,637^{\mathrm{a}}$ & & \\
\hline Marchador (MM) & 103 & 15 & $(14,6 \%)$ & & & \\
\hline Quarto de milha & 201 & 21 & $(10,4 \%)$ & & & \\
\hline Sem raça definida & 91 & 13 & $(14,3 \%)$ & & & \\
\hline \multicolumn{7}{|l|}{ Sexo } \\
\hline Fêmea & 165 & 21 & $(12,7 \%)$ & $0,908^{\mathrm{a}}$ & & \\
\hline Macho & 235 & 29 & $(12,3 \%)$ & & & \\
\hline \multicolumn{7}{|l|}{ Tipo de criação } \\
\hline A campo & 158 & 17 & $(10,8 \%)$ & $0,310^{\mathrm{b}}$ & & \\
\hline Estabulado & 101 & 17 & $(16,8 \%)$ & & & \\
\hline Semi-estabulado & 141 & 16 & $(11,3 \%)$ & & & \\
\hline \multicolumn{7}{|l|}{ Região } \\
\hline Sertão & 88 & 6 & $(6,8 \%)$ & $0,142^{a}$ & 1 & \\
\hline Agreste & 116 & 13 & $(11,2 \%)$ & & $1,7(0,6-4,7)$ & 0,290 \\
\hline RMR & 107 & 15 & $(14,0 \%)$ & & $2,2(0,8-6,0)$ & 0,113 \\
\hline Zona da Mata & 89 & 16 & $(18,0 \%)$ & & $3,0(1,1-8,0)$ & $0,029 *$ \\
\hline
\end{tabular}

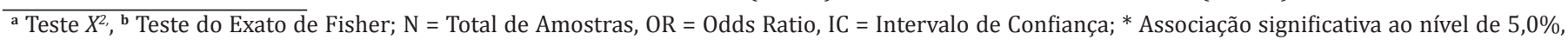
** Indefinido. 
A diferença na variação nas taxas de soroprevalência para T. gondii em equídeos pode ser justificada em função da utilização dos diferentes testes sorológicos utilizados, cepas de T. gondii, o estado imunitário dos animais, idade, manejo e procedência dos animais (Dubey \& Beattia 1988), aliado ao fator resistência natural dos equídeos à infecção por T. gondii (Mendonça et al. 2001).

No Brasil, outros estudos sorológicos já foram conduzidos utilizando-se técnicas como a reação de imunofluorescência indireta (Valença et al. 2015), hemaglutinação indireta (Barcelos et al. 1997) e teste de aglutinação modificado (Langoni et al. 2007).

Nesse sentido, Camossi et al. (2010) realizaram estudo utilizando RIFI e MAT, constatando que ambas as técnicas apresentam alta sensibilidade e especificidade. Entretanto, esses autores ressaltaram que há aspectos favoráveis relacionados com o MAT, como simplicidade da técnica e custo, e pelo fato de não haver necessidade de equipamentos sofisticados além da maior sensibilidade comparada à RIFI. Esse fato deve estar relacionado com diferentes subtipos de IgG detectados em cada teste sorológico, ou essas diferenças para baixas diluições do soro podem ser atribuídas a reações inespecíficas (Dubey 1985).

Assim, o teste de aglutinação modificado é uma técnica amplamente utilizada e validada para diferentes espécies animais, devido à facilidade de realização e concordância aos outros testes de diagnóstico, resultando em um maior número de resultados positivos e títulos ligeiramente mais altos quando comparados com a RIFI (Silva et al. 2002), sendo apontado como prova de escolha frente ao ELISA e à RIFI para o diagnóstico de anticorpos anti-T. gondii em ovinos (Seefeldt et al. 1989).

Neste estudo, a maior prevalência foi detectada na Zona da Mata (17,98\%; OR=3), seguida da Região Metropolitana do Recife (14,02\%; OR=2,2), Agreste $(11,21 \%$; OR=1,7) e Sertão $(6,82 \% ; 0 R=1)$.

Esta diferença pode ser justificada em virtude das diferenças climáticas existentes, pois o microclima da Zona da Mata e Região Metropolitana do Recife favorece a esporulação do oocisto de T. gondii e consequentemente a contaminação de alimentos, água e solo (Villena et al. 2012) e posterior infecção nos animais, diferente do Agreste e Sertão, cujo clima é seco e árido, com baixos índices pluviométricos, dificultando a viabilidade do agente no ambiente (Lúcio et al. 2016).

Não obstante, a infecção pelo T. gondii em gatos apresenta grande importância na vigilância epidemiológica sendo a presença destes animais um importante fator de risco, que pode quando em número de três ou mais gatos, aumentar em $70 \%$ o risco de infecção por T. gondii (Jones et al. 2009) nas espécies que co-habitam um determinado ambiente, notadamente em áreas metropolitanas do Brasil (Camargo et al. 1995)

Estudos realizados no Brasil, registraram uma associação entre as variáveis soropositividade à infecção e temperatura ambiente, sendo relatada que em temperaturas mais amena, umidade relativa alta, solo úmido e maior precipitação pluviométrica (Alves et al. 1997), observa-se maiores taxas de prevalência. Estas características são semelhantes às que ocorrem na Zona da Mata e Região Metropolitana do Recife, onde foram constatadas as maiores positividades no presente estudo.
Em função da não observância de diferença significativa na população de felinos, a prevalência de toxoplasmose em equinos em diferentes regiões aqui relatada, parece estar associada a fatores ambientais tais como umidade, temperatura e altitude (Gazêta et al.1997) que interferem na sobrevivência dos oocistos no ambiente por um longo período (Villena et al. 2004), e consequentemente a ocorrência da infecção (Amendoeira et al. 2003).

Contudo, deve ser levado em consideração o deslocamento dos animais entre as regiões (Langoni et al. 2007), já que boa parte dos animais aqui avaliados são atletas e participam de competições hípicas em diferentes localidades do Brasil. Além destes, alguns outros equídeos são criados livres às margens de rodovias e podem sofrer acidentes, sendo importante fonte de infecção para carnívoros e assim disseminarem a toxoplasmose no ambiente e para outras espécies (Alvarado-Esquivel et al. 2015).

Quanto ao tipo de criação, observou-se uma maior prevalência da infecção entre os animais estabulados (16,8\%), seguidos daqueles semi-estabulados $(11,3 \%)$ e a campo $(10,8 \%)$. Da mesma forma que justificado anteriormente, com relação à influência do ambiente, na sua grande maioria, os cavalos estabulados eram animais atletas, o que possibilita contato com diferentes ambientes contaminados.

Os animais estabulados eram alimentados com feno, o qual pode ter sido produzido inadequadamente ou mal armazenado fator que pode levar à contaminação com oocistos liberados nas fezes de felinos, particularmente gatos domésticos. Sabe-se que gatos tinham acesso aos armazéns de feno nas propriedades o que reforça a suspeita de contaminação. Apesar disso, a presença de gatos não foi significativa neste estudo, corroborando com Valença et al. (2015) que pesquisando os fatores de risco de ocorrência de toxoplasmose em equídeos no estado de Alagoas também não identificou esse como fator de risco.

Avaliando-se a variável idade, observou-se que a maior prevalência ocorreu nos animais adultos (2,5-11 anos) com $13,78 \%$ seguidos dos jovens $(<2,5$ anos) com $9,64 \%$ e por último os mais velhos ( $>11$ anos) que apresentaram $8,82 \%$ de positividade, sem significância estatística. Resultado semelhante foi relatado em estudo na Espanha onde foi observada uma maior soropositividade em equídeos adultos (García-Bocanegra et al. 2012).

Apesar de animais poderem se infectar em qualquer fase de sua vida (García-Bocanegra et al. 2012), é provável que a taxa de prevalência seja proporcional à idade do animal em função de maior exposição ao agente etiológico (Boughattas et al. 2011).

Por sua vez, quando avaliada a variável alimentação, também não foram observadas diferenças estatisticamente significativas neste estudo, corroborando com Oliveira Filho et al. (2012) que trabalhando com equídeos no Nordeste do Brasil também não encontrou diferenças.

A prevalência de anticorpos anti-T. gondii aqui observada $(12,5 \%)$ comprova a circulação do parasito na população de equídeos sendo um dado de grande relevância na saúde pública, pois, apesar de não existir o hábito de consumir carne de equídeos, o Brasil é oitavo maior exportador mundial do produto (Brasil 2016). 


\section{CONCLUSÃO}

A detecção de anticorpos IgG anti-Toxoplasma gondii revela a presença do parasito na área estudada, o que pode representar um elo na cadeia de transmissão da toxoplasmose a qual tem repercussão em saúde pública.

\section{REFERÊNCIAS}

Alvarado-Esquivel C., Alvarado-Esquivel D. \& Dubey J.P. 2015. Prevalence of Toxoplasma gondii antibodies in domestic donkeys (Equus asinus) in Durango, Mexico slaughtered for human consumption. BMC Vet. Res. 2015(11):6. http://dx.doi.org/10.1186/s12917-015-0325-9. PMid:25595816.

Alvarado-Esquivel C., Rodríguez-Peña S., Villena I. \& Dubey J.P. 2012. Seroprevalence of Toxoplasma gondii infection in domestic horses in Durango State, Mexico. J. Parasitol. 98(5):944-945. http://dx.doi.org/10.1645/ GE-3174.1. PMid:22559329.

Alves C.J., Vasconcelos S.A., Navarro I.T. \& Barbosa C.S. 1997. Avaliação dos níveis de aglutininas anti-toxoplasma em soros de caprinos de cinco centros de criação do nordeste do Brasil. Revta Bras. Ciênc. Vet., Heredia, 4(2):75-77.

Amendoeira M.R., Sobral C.A., Teva A., Lima J.N. \& Klein C.H. 2003. Inquérito sorológico para a infecção por Toxoplasma gondii em ameríndios isolados, Mato Grosso. Revta Soc. Bras. Med. Trop. 36(6):671-676. http://dx.doi. org/10.1590/S0037-86822003000600005. PMid:15049105.

Aspinall T.V., Marlee D., Hyde J.E. \& Sims P.F.G. 2002. Prevalence of Toxoplasma gondii in comercial meat products as monitored by polimerase chain reaction: food for thought? Int. J. Parasitol. 32(9):1193-1199. http://dx.doi. org/10.1016/S0020-7519(02)00070-X. PMid:12117502.

Balkaya I., Babur C., Celebi B. \& Utuk A.E. 2011. Seroprevalence of toxoplasmosis in donkeys in eastern Turkey. Isr. J. Vet. Med. 66:39-42.

Barcelos A.S., Lagaggio V.R.A., Cenci A., Colombo F.H., Katzer L.H. \& Noal S.A. 1997. Pesquisa de anticorpos anti-Toxoplasma gondii em equinos de Uruguaiana-RS-Brasil. IV Jornada Integrada de Pesquisa, Extensão e Ensino, Universidade Federal de Santa Maria, RS. 565p.

Boughattas S., Bergaoui R., Essid R., Aoun K. \& Bouratbine A. 2011. Seroprevalence of Toxoplasma gondii infection among horses in Tunisia. Parasit. Vectors 4(1):218. http://dx.doi.org/10.1186/1756-3305-4-218. PMid:22107730.

Braccini G.L., Chaplin E.L., Stobe N.S., Araújo F.A.P. \& Santos N.R. 1992. Resultados de exames laboratoriais realizados no setor de protozoologia da Faculdade de Veterinária da UFRGS, Porto Alegre, nos anos de 1986 a 1990. Arq. Fac. Vet. UFRGS 20:134-149.

Brasil 2016. Ministério da Agricultura, Pecuária e Abastecimento. Disponível em <http://www.agricultura.gov.br/animal/especies/equideos > Acessado em 12.10.2016.

Camargo M.C., Antunes C.M. \& Chiari Cde.A. 1995. Epidemiologia da infecção por Toxoplasma gondii no município de Ribeirão das Neves, MG. I. Importância dos animais domésticos como fonte de infecção de T. gondii para o homem. Revta Soc. Bras. Med. Trop. 28(3):211-214. http://dx.doi.org/10.1590/ S0037-86821995000300008. PMid:7480915.

Camossi L.G., Silva A.V. \& Langoni H. 2010. Inquérito sorológico para toxoplasmose em equinos da região de Botucatu. Arq. Bras. Med. Vet. Zootec. 62(2):484-488. http://dx.doi.org/10.1590/S0102-09352010000200032.

Carletti R.T., Contente A.P.A., Navarro I.T., Prudencio L.B., Tsutsui V.S., Marana E.R.M. \& Romão G.O. 2002. Surto de toxoplasmose em Santa Isabel do Ivaí, PR, Brasil: sorologia em animais domésticos. XXIX Congresso Brasileiro de Medicina Veterinária, Gramado, p.60.

Coiro C.J., Langoni H. \& Silva R.C. 2012. Epidemiological Aspects in the Leptospira spp. and Toxoplasma gondii Infection in Horses from Botucatu, São Paulo, Brazil. J. Equine Vet. Sci. 32(10):620-623. http://dx.doi.org/10.1016/j. jevs.2012.02.008.
Costa A.J., Ishizuca M.M., Mrque L.C., Vidotto O., Rocha U.F. \& Ikeda A. 1986. Toxoplasmosis frequency in equines from the North region of São Paulo State, Brazil. Ars Vet. 2(1):75-79.

Desmonts G. \& Remington J.S. 1980. Direct agglutination test for diagnosis of Toxoplasma infection: method for increasing sensitivity and specificity. J. Clin. Microbiol. 11(6):562-568. PMid:7000807.

Dubey J.P. \& Beattia C.P. 1988. Toxoplasmosis of Animals and Man. CRC Press. Boca Raton, FL. 220p.

Dubey J.P. \& Jones J.L. 2008. Toxoplasma gondii infection in humans and animals in the United States. Int. J. Parasitol. 38(11):1257-1278. http:// dx.doi.org/10.1016/j.ijpara.2008.03.007. PMid:18508057.

Dubey J.P. 1985. Persistence of encysted Toxoplasma gondii in tissues of equids fed oocysts. Am. J. Vet. Res. 46(8):1753-1754. PMid:4037503.

Dubey J.P., Ness S.L., Kwok O.C., Choudhary S., Mittel L.D. \& Divers T.J. 2014. Seropositivity of Toxoplasma gondii in domestic donkeys (Equus asinus) and isolation of T. gondii from farm cats. Vet. Parasitol. 199(1/2):18-23. http://dx.doi.org/10.1016/j.vetpar.2013.09.027. PMid:24140163.

Evers F., Garcia J.L., Navarro I.T., Zulpo D.L., Nino B.S.L., Ewald M.P.C., Pagliari S., Almeida J.C. \& Freire R.L. 2013. Diagnosis and isolation of Toxoplasma gondii in horses from Brazilian slaughterhouses. Revta Bras. Parasitol. Vet. 22(1):58-63. http://dx.doi.org/10.1590/S1984-29612013005000009. PMid:23538498.

Garcia J.L., Navarro I.T., Ogawa L. \& Oliveira R.C. 1999. Soroprevalência do Toxoplasma gondii, em suínos, bovinos, ovinos e equinos, e sua correlação com humanos, felinos e caninos, oriundos de propriedades rurais do norte do Paraná, Brasil. Ciência Rural 29(1):91-97. http://dx.doi.org/10.1590/ S0103-84781999000100017.

García-Bocanegra I., Cabezón O., Arenas-Montes A., Carbonero A., Dubey J.P., Perea A. \& Almería S. 2012. Seroprevalence of Toxoplasma gondii in equids from Southern Spain. Parasitol. Int. 61(3):421-424. http://dx.doi. org/10.1016/j.parint.2012.02.003. PMid:22366344.

Gazêta G.S., Dutra A.E.A., Norberg A.N., Serra-Freire N.M., Souza W.J.S., Amorim M. \& Lopes L.M.S. 1997. Frequência de anticorpos anti-Toxoplasma gondii em soros de equinos no Estado do Rio de janeiro, Brasil. Revta Bras. Parasitol. Vet. 6(2):87-91.

Gharekhani J. 2014. Toxoplasma gondii Infection in domestic animals in Hamedan, Iran: a sero-epidemiological study. Bull. UASVM Vet. Med. 71(1):68-72.

Ghazy A.A., Shaapan R.M. \& Abdel-Rahman E.H. 2007. Comparative serological diagnosis of toxoplasmosis in horses using locally isolated Toxoplasma gondii. Vet. Parasitol. 145(1/2):31-36. http://dx.doi.org/10.1016/j. vetpar.2006.11.010. PMid:17174034.

Hejlíček K. \& Literák I. 1994. Prevalence of antibodies to Toxoplasma gondii in horses in the Czech Republic. Acta Parasitol. 39(4):217-219.

IBGE 2006. Instituto Brasileiro de Geografia e Estatística. Disponível em <http://www.ibge.gov.br/estadosat/temas.php?sigla=pe\&tema=censoagro> Acessado em 22.10.2016.

IBGE 2010. Instituto Brasileiro de Geografia e Estatística. Disponível em <http://www.ibge.gov.br/estadosat/perfil.php?lang=\&sigla=pe> Acessado em 19.11.2016.

Ishizuka M.M., Miguel O. \& Brogliato D.F. 1975. Avaliação da prevalência de anticorpos anti-Toxoplasma em eqüinos PSI clinicamente normais. Revta Fac. Med. Vet. Zootec. USP 12(1):289-292. http://dx.doi.org/10.11606/ issn.2318-3659.v12i1p289-292.

Jakubek E.B., Lunden A. \& Uggla A. 2006. Seroprevalences of Toxoplasma gondii and Neospora spp. infections in Swedish horses. Vet. Parasitol. 138(3/4):194-199. http://dx.doi.org/10.1016/j.vetpar.2006.02.002. PMid:16517077. 
Jones J.L., Dargelas V., Roberts J., Press C., Remington J.S. \& Montoya J.G. 2009 Risk factors for Toxoplasma gondii infection in the United States. Clin. Infect. Dis. 49(6):878-884. http://dx.doi.org/10.1086/605433. PMid:19663709.

Karatepe B., Babür C., Karatepe M. \& Kiliç S. 2010. Seroprevalence of toxoplasmosis in horses in Niğde Province of Turkey. Trop. Anim. Health Prod. 42(3):385-389. http://dx.doi.org/10.1007/s11250-009-9430-8. PMid:19701805.

Kouam M.K., Diakou A., Kanzoura V., Papadopoulos E., Gajadhar A.A. \& Theodoropoulos G. 2010. A seroepidemiological study of exposure to Toxoplasma, Leishmania, Echinococcus and Trichinella in equids in Greece and analysis of risk factors. Vet. Parasitol.170(1/2):170-175. http://dx.doi. org/10.1016/j.vetpar.2010.02.004. PMid:20197215.

Langoni H., Silva A.V., Pezerico S.B. \& Lima V.Y. 2007. Utilization of modified agglutination test and indirect immunofluorescent antibody test for the detection of Toxoplasma gondii antibodies in naturally exposed horses. Braz. J. Vet. Res. Anim. Sci. 44(1):27-32. http://dx.doi.org/10.11606/ issn.1678-4456.bjvras.2007.26657.

Larangeira N.L., Ishizuka M.M. \& Hyakutake S. 1985. Prevalência da toxoplasmose equina avaliada pela técnica de imunofluorescência indireta, Mato Grosso do Sul, Brasil. Bol. Oficina Sanit. Panam. 99(2):158-162. PMid:2935168.

Locatelli-Dittrich R., Dittrich J.R., Richartz R.R.T.B., Gasinojoineau M.E., Antunes J., Pinckney R.D., Deconto I., Hoffmann D.C.S. \& Thomaz-Soccol V. 2006. Investigation of Neospora sp. and Toxoplasma gondii antibodies in mares and in precolostral foals from Parana state. Vet. Parasitol. 135(3/4):215221. http://dx.doi.org/10.1016/j.vetpar.2005.10.010. PMid:16289863.

Lúcio E.C., Santos S.M.C., Pimentel J.L., Albuquerque R.A.M., Oliveira J.M.B., Silva Júnior J.L., Albuquerque P.P.F., Mota R.A. \& Pinheiro Junior J.W. 2016. Análise epidemiológica da infecção por Toxoplasma gondii em caprinos no estado de Pernambuco, Brasil. Revta Bras. Med. Vet. 38(1):13-18.

Mendonça A.D.O., Cerqueira E.J.L., Araujo W.N., Silva E.M., Shimabukuro F.H., Sarkis D.T., Sherlock Í. \& Langoni H. 2001. Inquérito sorológico para toxoplasmose em equídeos procedentes de duas regiões do estado da Bahia, Brasil. Semina: Ciênc. Agrár. 22(2):115-118. http://dx.doi. org/10.5433/1679-0359.2001v22n2p115.

Miao Q., Wang X., She L.N., Fan Y.T., Yuan F.Z., Yang J.F., Zhu X.Q. \& Zou F.C. 2013. Seroprevalence of Toxoplasma gondii in horses and donkeys in Yunnan Province, southwestern China. Parasit. Vectors 6(1):168. http:// dx.doi.org/10.1186/1756-3305-6-168. PMid:23742078.

Moura A.B., Matiello J.P., Silva M.O., Souza A.P. \& Sartor A.A. 2016. Antibodies against Toxoplasma gondii in horses from the coastal and mountain mesoregions of the state of Santa Catarina, Brazil. Semina, Ciênc. Agrárias 37(1):203-211. http://dx.doi.org/10.5433/1679-0359.2016v37n1p203.

Navarro I.T., Freire R.L., Carletti R.T., Contente A.P.A., Navarro I.T., Prudencio L.B., Tsutsui V.S., Marana E.R.M. \& Romão G.O. 2002. Surto de toxoplasmose em Santa Isabel do Ivaí, PR, Brasil: sorologia em animais domésticos. XII Congresso Brasileiro de Parasitologia Veterinária, Rio de Janeiro.

Naves C.S., Ferreira F.A., Carvalho F.S. \& Costa G.H. 2005. Soroprevalência da toxoplasmose em equinos da raça mangalarga marchador no município de Uberlândia, Minas Gerais. Vet. Noticias 11(1):45-52.

Oliveira E., Albuquerque P.P.F., Souza Neto O.L., Faria E.B., Pinheiro Júnior J.W. \& Mota R.A. 2013. Occurrence of antibodies to Toxoplasma gondii in mules and donkeys in northeast Brazil. J. Parasitol. 99(2):343-345. http:// dx.doi.org/10.1645/GE-3210.1. PMid:22924911.

Oliveira Filho R.B., Malta K.C., Oliveira J.M.B., Albuquerque P.P.F., Mota R.A., Santana V.L.A., Alves L.C. \& Pinheiro Junior J.W. 2012. Epidemiological situation of Toxoplasma gondii infection in equids from Brejo Paraibano microregion. Pesq. Vet. Bras. 32(10):995-1000. http://dx.doi.org/10.1590/ S0100-736X2012001000008.

Rinaldi L. \& Scala A. 2008. Toxoplasmosis in livestock in Italy: an epidemiological update. Parassitology 50(1/2):59-61. PMid:18693559.

Seefeldt S.L., Kirkbride C.A. \& Dubey J.P. 1989. Comparison of enzyme-linked immunosorbent assay, indirect fluorescent antibody test, and direct agglutination test for detecting Toxoplasma gondii antibodies in naturally aborted ovine fetuses. J. Vet. Diagn. Invest. 1(2):124-127. http://dx.doi. org/10.1177/104063878900100206. PMid:2488330.

Silva A.V., Cutolo A.A. \& Langoni H. 2002. Comparação da reação de imunofluorescência indireta e do método de aglutinação direta na detecção de anticorpos anti-Toxoplasma em soros de ovinos, caprinos, caninos e felinos. Arqs Inst. Biológico, São Paulo, 69(1):7-11.

Silva N.R.S., Chaplin E.L., Araujo F.A.P. \& Pereira R.A.P. 1981. Prevalência de anticorpos toxoplásmicos em soros de equinos no município de Porto Alegre, RS. Arqs Fac. Vet. UFRGS 9:105-107.

Tassi P. 2007. Toxoplasma gondii infection in horses: a review. Parassitology 49(1/2):7-15. PMid:18412038.

Tavalla M., Sabaghan M., Abdizadeh R., Khademvatan S., Rafiei A. \& Razavi Piranshahi A. 2015. Seroprevalence of Toxoplasma gondii and Neospora spp. infections in Arab horses Southwest of Iran. Jundishapur J. Microbiol. 8(3): e14939. http://dx.doi.org/10.5812/jjm.14939. PMid:25834714.

Tenter A.M., Heckeroth A.R. \& Weiss L.M. 2000. Toxoplasma gondii: from animals to humans. Int. J. Parasitol. 30(12/13):1217-1258. http://dx.doi. org/10.1016/S0020-7519(00)00124-7. PMid:11113252.

Uggla A., Mattson S. \& Juntti N. 1990. Prevalence of antibodies to Toxoplasma gondii in cats, dogs and horses in Sweden. Acta Vet. Scand. 31(2):219-222. PMid:2260515.

Valença S.R.F.A., Valença R.M.B., Pinheiro Junior J.W., Albuquerque P.P.F., Souza Neto O.L. \& Mota R.A. 2015. Risk factors for occurrence of antiNeospora spp. antibodies in horses from Alagoas, Brazil. J. Equine Vet. Sci. 35(11/12):917-921. http://dx.doi.org/10.1016/j.jevs.2015.08.014.

Vidotto O., Kano F.S., Freire R.L., Mitsuka R., Ogawa L., Banesi G., Navarro I.T. \& Franciscon F.S.G. 1997. Ocorrência de anticorpos anti-Toxoplasma gondii em equinos procedentes de quatro Estados (SP, PR, MS e MT) abatidos em Apucarana, PR. Semina, Ciênc. Agrárias 18(1):9-13.

Villalobos E.M.C., Lara M.C.C.S.H., Cunha E.M.S. \& Soares R.M. 2005. Ocorrência de anticorpos anti-Toxoplasma gondii em soro de equídeos oriundos de propriedades da região do Vale do Ribeira, estado de São Paulo e abatidos em matadouro no estado do Paraná. Arqs Inst. Biológico, São Paulo, 72(2):1-64.

Villena I., Aubert D., Gomis P., Ferté H., Inglard J.C., Denis-Bisiaux H., Dondon J.M., Pisano E., Ortis N. \& Pinon J.M. 2004. Evaluation of a strategy for Toxoplasma gondii oocyst detection in water. Appl. Environ. Microbiol. 70(7):4035-4039. http://dx.doi.org/10.1128/AEM.70.7.4035-4039.2004. PMid:15240280.

Villena I., Durand B., Aubert D., Blaga R., Geers R., Thomas M., Perret C., Alliot A., Escotte-Binet S., Thébault A., Boireau P. \& Halos L. 2012. New strategy for the survey of Toxoplasma gondii in meat for human consumption. Vet. Parasitol. 183(3/4):203-208. http://dx.doi.org/10.1016/j.vetpar.2011.08.001. PMid:21864981.

Webster J.P. 2010. Review of "toxoplasmosis of animals and humans. Parasit. Vectors 3(1):112. http://dx.doi.org/10.1186/1756-3305-3-112. 